\title{
MEMORIAS DE TÉ: CONVERSACIONES CON GUACOLDA BOISSET MUJICA
}

\author{
Benjamín Ballester Riesco ${ }^{1}$
}

\begin{abstract}
VIDA
Guacolda América Boisset Mujica nació en Santiago de Chile el 25 de mayo de 1929. Su formación académica estuvo inicialmente vinculada a las Leyes y las Bellas Artes, mientras que su primer acercamiento hacia el área de la Antropología y Arqueología fue al alero del Centro de Estudios Antropológicos (formado en 1954) de Santiago. Aquí colaboró con quien ella misma definía como una de sus mejores y más cercanas amigas, Ingeborg Lindberg. Desde ese espacio y con esa compañía recorrió el norte de Chile haciendo arqueología con sus propios recursos, visitando los sitios arqueológicos del valle de Camarones, Quillagua y San Pedro de Atacama.

A comienzos de los sesenta parte a México a estudiar arqueología en la Escuela Nacional de Antropología e Historia (ENAH), donde obtendría en 1968 su maestría titulada El Formativo americano en la costa del Pacífico. Este título la convirtió en la primera mujer chilena en obtener un postgrado en Arqueología, y más allá de las diferencias de género, en la segunda luego del Dr. Bernardo Berdichewsky (1961). Durante su estadía en el hemisferio norte trabaja con investigadores de renombre internacional como Richard MacNeish y Román Piña Chan, y en sitios arqueológicos como los del islote de Jaina en Campeche. Estando en México fue nombrada Cónsul Honoraria durante el año 1963.

Sin terminar sus estudios en México Gustavo Le Paige la convence para hacerse cargo de la creación de la Carrera de arqueología y antropología de la Universidad del Norte, sede Antofagasta, en colaboración con Bernardo Tolosa que trabajaba en el museo y el jesuita Miguel Squella de la universidad. La iniciativa comienza en 1967, pero solo en 1972 se ve cristalizada en la apertura de la carrera. Como parte del proyecto se le encomienda crear un programa académico, definir su malla y los
\end{abstract}

cursos que le darían forma, para lo cual toma como maqueta su experiencia de formación profesional en la ENAH de México. Así, la carrera se concibe como un plan común que reunía en los primeros años a antropólogos y arqueólogos. Una réplica académica que pondría a la arqueología a un costado de la antropología, a diferencia de lo que ocurría en la Universidad de Chile de Santiago donde la arqueología nacía algunos años antes del alero de la Historia y al amparo de las Humanidades (Orellana 1993, 1996). Tendencia que con el paso de las décadas se afianzaría en la identidad de la formación universitaria de la arqueología chilena, hoy más cerca de la Antropología que de la Historia, heredera más próxima de las escuelas norteamericanas que europeas.

Su inserción en la academia chilena no fue algo sencillo, menos hacerlo en el Norte de Chile. Arribar con estudios internacionales de posgrado en Arqueología y ser santiaguina de toda la vida en una tierra de investigadores que profesaban el localismo nortino (Montané et al. 1972) le pusieron cuesta arriba la tarea. Esto fue aún más complejo considerando que la arqueología de aquellos años estaba dominada y controlada casi exclusivamente por hombres ${ }^{1}$, generando roces inmediatos y enemistades, dificultando la formación de la carrera y su propio devenir como investigadora.

Para poner en marcha la maquinaria académica logró que la universidad contratara personal dedicado a realizar los cursos de docencia. De la camada de antropólogos de la Universidad de Concepción trajo a Víctor Bustos y Orlando Campana, mientras que del Centro de Estudios Antropológicos de Santiago invitó a Emilia Salas. En ese entonces incorporó de planta a quien sería uno de los personajes más importantes de la arqueología antofagastina, al en ese entonces estudiante de biología, Agustín Llagostera.

Paralelamente al mundo docente comienzan sus labores de investigación en la arqueología nortina.

\footnotetext{
$\overline{1}$ ICIIS - Centro Interdisciplinario de Estudios Interculturales e Indígenas. Pontificia Universidad Católica de Chile, Santiago, Chile. benjaminballesterr@gmail.com
} 
Realizó proyectos de reconocimiento y excavación a lo largo de la costa desértica desde Cobija hasta Taltal, destacando aquellos en Chacaya, Los Canastos y Hornitos. Pero sin lugar a dudas su trabajo más conocido, aquel que ocupa el sitial más importante en la historia de nuestra arqueología, es el realizado en la caleta de Abtao, particularmente del sitio de Abtao 1 (Boisset 1972; Boisset y Llagostera 1971; Boisset et al. 1969, 1971). Este sitio había sido mencionado anteriormente solo por Junius Bird (1943:180), quien en sus 10 días de trabajo entre la bahía de Antofagasta y Punta Jorge destacaba este notorio promontorio de basuras como uno de los más prometedores sitios arqueológicos de la región. Aquí Guacolda logró imprimir todos sus conocimientos científicos en la excavación de un conchal a la manera como nos lo había enseñado décadas atrás el mismo arqueólogo norteamericano (Bird 1943, 1946) $)^{2}$, cuidadosa de los estratos depositacionales y preocupados por las variables tecnológicas de la secuencia. Tal fue su pulcritud científica que se convirtió en la primera investigadora chilena en tomar fechados radiocarbónicos desde sitios habitacionales en el norte de Chile, para el ordenamiento cronológico de las ocupaciones (Boisset y Llagostera 1971) ${ }^{3}$.
En este proceso de docencia universitaria fundó las bases académicas para la formación de algunos de los más importantes arqueólogos que hoy en día trabajan en el norte de Chile en universidades, museos y municipalidades, aquella camada de arqueólogos titulados de la ex-Universidad del Norte sede Antofagasta.

El golpe de Estado de 1973 y la dictadura militar clausuró la carrera de antropología y el ingreso a nuevos estudiantes a arqueología, en este último caso permitiendo titularse solo a algunos de los estudiantes. Esto, sumado a los trágicos acontecimientos sociales y humanos, terminaron sellando de golpe la arqueología y parte de la vida para Guacolda Boisset. Ante su experiencia personal y las decepciones con los acontecimientos deja para siempre la arqueología, la Universidad y Antofagasta, para relegarse en una casa familiar en el sector de Vichuquén en la VII Región del país. Ahí se mantuvo en gran medida al margen de la academia, escribiendo solo un libro relativo a los indígenas de la VII Región (Boisset 1985). Sorpresivamente a fines de 2015 emprendió la tarea de escribir una monografía de su trabajo en Abtao, algo necesario para cerrar un ciclo que felizmente alcanzó a terminar.

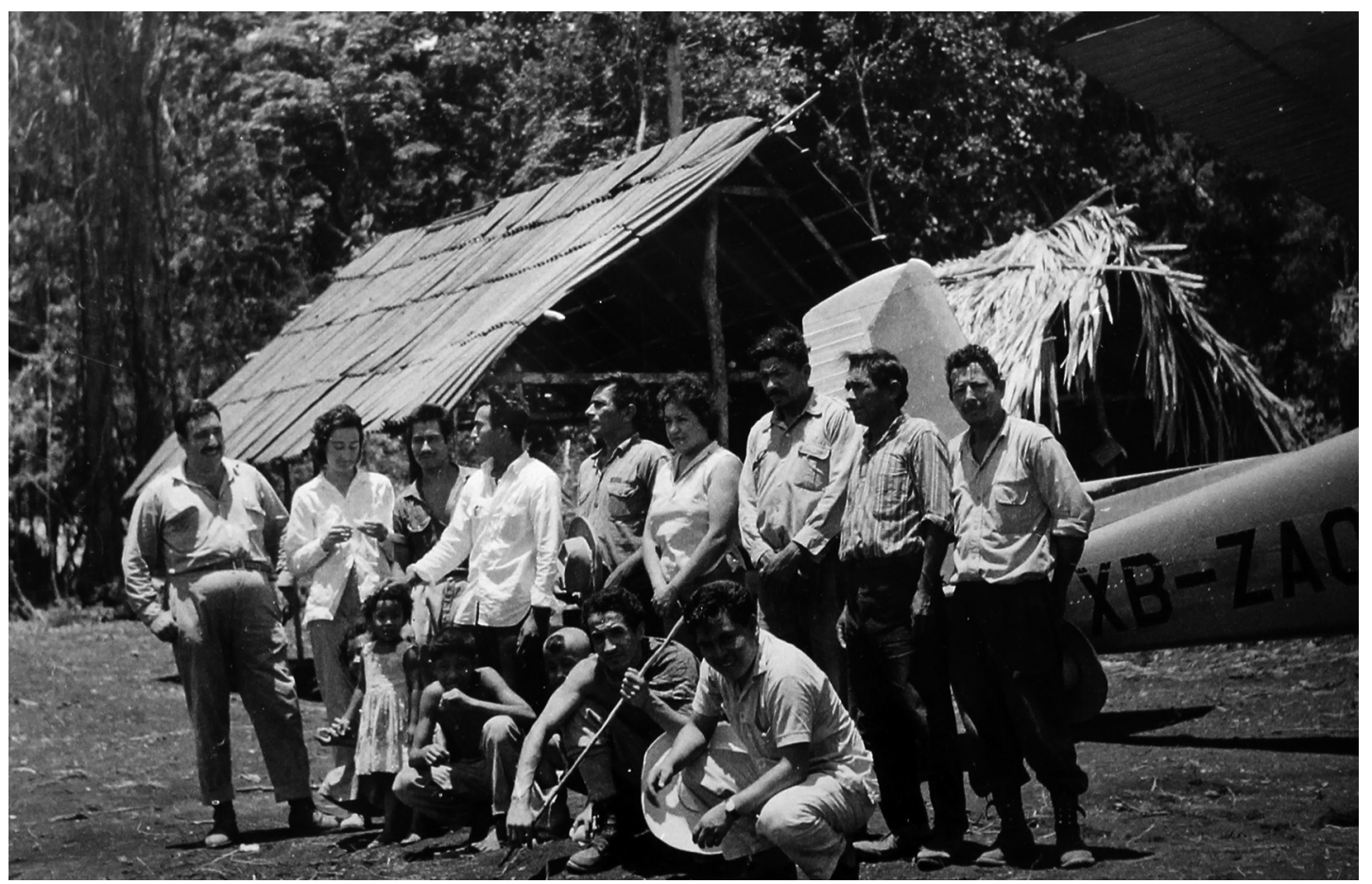

La selva tropical mesoamericana cobijó a Guacolda Boisset en sus años de formación profesional como arqueóloga (ca. 1963) (Colección Familia Pizarro Boisset). 
El 19 de enero de 2016 fallece a los 86 años de edad en Santiago.

\section{TÉ}

Nunca pensé que mi frenética y casi enfermiza adicción a los libros me haría conocer a personas que calen tanto en mi memoria. A mediados de 2014 recorría como de costumbre Mercadolibre en busca de libros de antropología cuando encontré un título que solo poseía como una roñosa fotocopia de otra fotocopia que había conseguido en la biblioteca del Museo Nacional de Historia Natural, la Etnografía e Historia del Mundo Andino, editado por Shozo Masuda (1986). No dudé en comprarlo, especialmente por ese fabuloso ensayo de Bente Bittmann sobre los Recursos renovables de la costa Norte de Chile: modos de obtención y uso. Al día siguiente me reuní con su vendedora en una estación de metro en el centro de la capital.

La transacción podría haber sido como de costumbre, fría aunque agradecida por el ansiado libro, pero por alguna razón continuamos conversando. Creo que fue el tema del libro, la antropología. Al parecer le conté que era arqueólogo y lo interesado que estaba en la temática, por lo que cualquier otro libro similar que tuviera por ahí podía enviármelo por email, tal vez me conquistaba. Inesperadamente en ese momento la conversación se expandió a algo inusitado: su madre era arqueóloga. Inmediatamente captó mi atención, lanzándole múltiples preguntas acerca de quién se trataba. Al escuchar a Guacolda Boisset mi interés se multiplicó. Siempre fue una incógnita para mí su devenir y paradero luego de su famoso trabajo en Abtao publicado hace poco más de 45 años - para quien no lo sepa, un pequeño balneario ubicado frente a la ciudad de Antofagasta al norte del país-.

La arqueología del litoral desértico del norte de Chile siempre ha sido para mí un placer culpable, y lo que lleve a saber más de ella me será inevitablemente una debilidad. Luego de charlar unos minutos le pregunté si era posible conocerla, explicándole que había estudiado en el Museo de Antofagasta parte de la colección que ella misma había excavado a finales de la década del sesenta. Contestó que su madre se había alejado de la arqueología por asuntos personales y que era un tema del que no solía hablar con regularidad, pero finalmente accedió y quedamos de acuerdo en una fecha para mi visita.

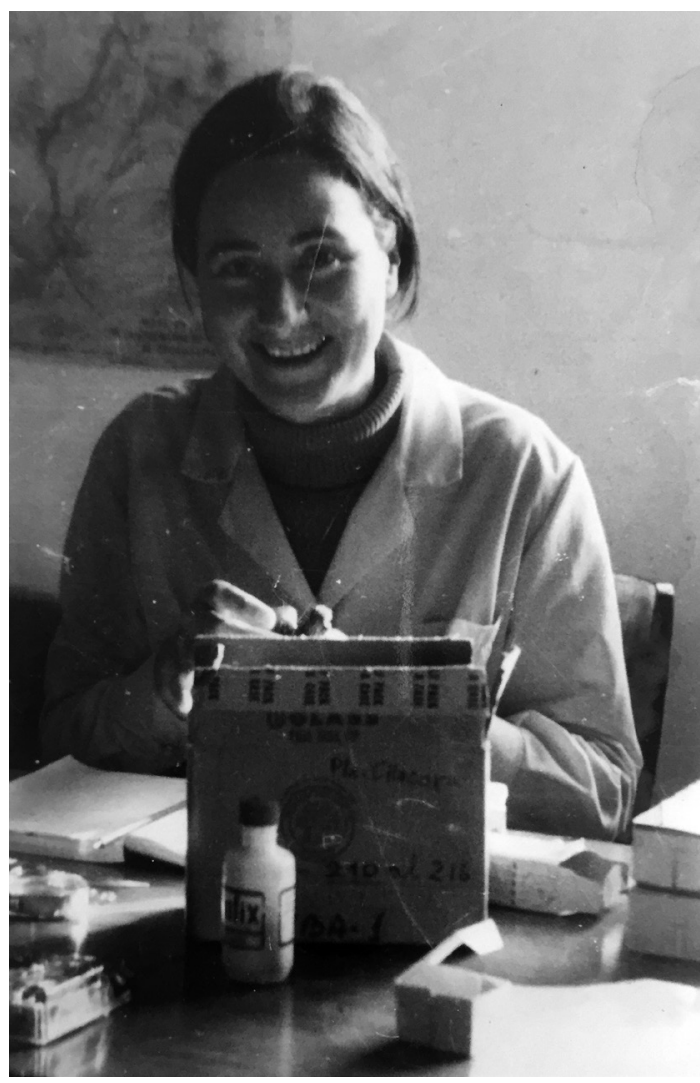

Guacolda Boisset catalogando y guardando cuidadosamente los materiales arqueológicos del cementerio de Punta Chacaya en Mejillones, enero de 1970 (Colección Familia Pizarro Boisset).

Impaciente, aunque con dudas, planifiqué el encuentro. Qué hablar y qué no, cómo comenzar y qué decir. Mis principales dudas se dirigían hacia su repentina ausencia, más bien, su literal desaparición. Para mí una incógnita absoluta, aunque las fechas me hacían presagiar lo peor, ya que todo sucedió antes de la primera mitad de los setenta. Daba la casualidad que vivíamos relativamente cerca, así que pude ir a pie y pensar todo el camino qué decir, cómo presentarme y ordenar un poco mi cabeza. Iba nervioso como si fuera a reunirme con alguna autoridad. Y lo era, aunque escueta, por su relevante trabajo y no por una larga trayectoria.

Recuerdo la casa. Tanto así que nunca más tuve que preguntar la dirección para llegar. Al tocar el timbre salió una perrita de color café teñida en su hocico por el paso de los años, me olfateó a través de la puerta semiabierta, que seguido de un lejano "pase" atravesé para ingresar al patio. La casa ñuñoína era grande, de aquellas antiguas en las que se intuye ha vivido más de una generación. Y así era. Un niño deambulaba 
por la casa, su madre -Javiera, con quien me había encontrado días antes en el metro para comprar el libro-me recibió en la puerta para hacerme pasar al living, y al cabo de unos minutos apareció Guacolda: madre, abuela y, para mí, arqueóloga.

Me recibió en el living de la casa luego de una breve espera. Era una mujer de edad, de tez blanca y pelo teñido por la vejez. Alta, delgada, distinguida, siempre de lentes y acompañada de un hablar ronco que ocultaba el dulzor de su voz. Me presenté explicando mi interés en conocerla, lo que le cambió de inmediato su cara, llena de una mezcla entre extrañez y entusiasmo. De inmediato comenzamos a conversar. Le comenté que quería conocer su historia personal en la arqueología antofagastina, además de los personajes y devenires de la arqueología chilena; todo aquello que ha quedado relegado de la tendenciosa Historia Formal escrita por nuestros propios historiadores. Un intento por revivir la memoria oral de la arqueología chilena para reescribirla, en especial de los actores que quedaron desterrados y los eventos que fueron invisibilizados.

En total nos logramos reunir tres veces a conversar, en distintas épocas y según nuestras propias agendas lo permitían. Las visitas fueron por las tardes, cuando bajaba el calor, donde aprovechábamos de tomar té y comer tostadas con palta a la sombra de un frondoso parrón en el patio trasero, infraestructura típica e infaltable de las antiguas casas ñuñoínas. Nuestras conversaciones comenzaron circulando en torno a su historia de acercamiento a la arqueología chilena, especialmente del Centro de Estudios Antropológicos. Quiénes eran sus miembros, a quiénes recordaba, cuáles de ellos habían estudiado carreras profesionales y cuáles eran simplemente aficionados, qué lugares visitaron y qué temas les interesaban. Gracias a contactos familiares con la fuerza aérea ella lograba conseguir viajes hacia el norte de Chile, donde recorrieron y ficharon los sitios arqueológicos del valle de Camarones, Quillagua y San Pedro de Atacama, oasis donde conoció a Gustavo Le Paige.

Sobre su relación con este último recuerdo una curiosa anécdota que me relató. A mediados de los sesenta Le Paige visitó Santiago, instancia en la que aprovechó de ir a su casa para ofrecerle trabajo en la Universidad del Norte sede Antofagasta con la idea de armar la carrera de Arqueología. A Guacolda le marcó tremendamente esa imagen de ver a su padre, un masón de aquellos a la antigua, anticlerical y socialista, haciendo pasar a un cura jesuita a su casa. A la entrada su padre le advirtió de antemano a Le Paige que se trataba de una casa de masones, donde se respetaban ciertas ideas y valores, y no necesitaban ningún tipo de consejos morales. La escena la recordaba con una enorme sonrisa en su cara, como si se hubiera estado riendo en silencio todas estas décadas del singular encuentro, del choque entre su formal padre y un cura que hacía arqueología en un pueblito en la mitad del desierto, de su historia de vida familiar y su pasión por la arqueología.

Seguimos conversando sobre su estadía y estudios en México. La necesidad de poseer una formación de calidad en arqueología, científica y profesional, no amateur y aficionada, destacando lo elevado del nivel que se tenía allá en comparación con Chile por aquellos años. El litoral siempre fue su tema, donde el mar y la costa constantemente surcaban sus anécdotas, historias y mejores cuentos. A veces pienso que ese parrón ñuñoíno aún atesoraba para su mirada lejana un poco del mar del desierto.

Recordaba con nostalgia esos años de formación de la carrera universitaria. Fueron tiempos de trabajo y desafíos personales, donde la sociedad se pensaba a sí misma, una instancia única para poder plasmar todos sus conocimientos acumulados en México y en el campo. En sus palabras y gestos yacía todavía la pasión que dedicó a estas labores; las ganas, el deseo, el proyecto y el ímpetu revivían en cada recuerdo. En sus relatos habían personajes cargados de intimidad y cariño, bañados de respeto e inundados de confianza: su padre, su amiga Ingeborg, Gustavo Le Paige, Emilia Salas, Agustín Llagostera y Orlando Campana. Su hija y su marido ocupaban lugares especiales.

Su cara cambió radicalmente cuando cruzamos los recuerdos que revivían el momento del golpe de Estado de 1973. En ese instante su quiebre anímico y sentimental fue tal que contagió viralmente mi propia sensibilidad. Los recuerdos pasaron de entregarnos una conversación fluida llena de risas, a dilatar silencios y dejarme personalmente sin palabras. Sus ojos, aun con los lentes de sol puestos, se notaban a través del vidrio opaco inundados de lágrimas contenidas. Sin palabras ni detalles sobre el porqué, el mero gesto lo explicaba. Sin preguntarlo noté cómo todo aquello que había llenado tantos espacios en su vida, eso que le permitió realizarse profesional y socialmente, se había desplomado dejando heridas que aún seguían sin sanar. En un escenario anímico como ese decidí no ahondar en profundidad, tampoco había gran necesidad, pero 
por voluntad propia ella misma fue poco a poco liberando recuerdos que fueron dando sentido a su respuesta presente de la reconstrucción de ese momento pasado.

Los primeros recuerdos los protagonizaban los militares y sus armas en la universidad, la desaparición de colegas de trabajo, la preocupación por los alumnos, la quema de libros en los espacios públicos y la incertidumbre en el futuro, por próximo que fuera. De sus palabras desprendo que para ella fue como un terremoto que tiró por tierra todo aquello que con tanto ímpetu había construido con amigos, cercanos y colegas. Todo al suelo, llevándose gente consigo.

Con los fusiles sentados en los puestos de intelectuales la orgánica de la universidad cambió para siempre. Se cerró la carrera de antropología y en arqueología solo se permitió que "dentro de ciertas condiciones" terminaran algunos de los que habían comenzado. Guacolda no pudo aceptar la violación del proyecto social, universitario y académico, no solo por los agravios físicos personales a colegas, funcionarios y estudiantes, sino también por todo aquello que habían construido con la arqueología y las ciencias sociales dentro de un proyecto de sociedad. No estuvo dispuesta a participar, por mucho que eso le costara dejar de lado su vida y relegar su ser social. Algo que hizo, llevándola a tomar el camino del autoexilio de la academia ahora nombrada con el dedo por los generales y al servicio de un grupo reducido de personas. Nunca más volvió a hacer arqueología, se radicó en un fundo familiar en el centro-sur del país, lejos de los investigadores y la academia.

Sentimientos de frustración, pena y pérdida se dibujaban en su cara y oían tras su voz a ratos temblorosa. Cuando llegamos a este tema ya llevábamos al menos un par de horas conversando, tiempo en que las hojas de té aprovecharon de descansar tranquilamente remojándose en la tetera. Esto hizo que los últimos sorbos de la taza fueran amargos y ásperos, como nuestros últimos momentos de conversación, culpa de los recuerdos y del tiempo, pecado de la memoria.

Espero que esto nos ayude a recodar que como el té, la vida trae momentos dulces y agraces. Ojalá al menos eso sí nos quede bien grabado en la memoria.

Saludos Guacolda.

\section{Referencias Citadas}

Bird, J. 1943. Excavations in northern Chile. Anthropological Papers of the American Museum of Natural History 38(4):173-318.

Bird, J. 1946. The cultural sequence of the north chilean coast. En Handbook of South American Indians, editado por J. Steward, Vol. II, pp. 587-594. Smithsonian Institution, Washington, DC.

Boisset, G. 1968. El Formativo Americano en la Costa del Pacífico. Memoria de Maestría ENAH, México, DF.

Boisset, G. 1972. Problemática cultural de Caleta Abtao, Antofagasta. Actas y Memorias del XXXIX Congreso Internacional de Americanistas. Instituto de Estudios Peruanos, Lima.

Boisset, G. 1985. Origen y Significado del Vocablo Vichuquén. Editorial América, Santiago.

Boisset, G. y A. Llagostera 1971. Fechas radiocarbónicas de Caleta Abtao - Comparación con otras fechas de sitios costeros. Resúmenes del VI Congreso Nacional de Arqueología Chilena. Universidad de Chile, Santiago.

Boisset, G., A. Llagostera y E. Salas 1969. Excavaciones arqueológicas en Caleta Abtao. Antofagasta. Actas del V Congreso Nacional de Arqueología, pp. 75-152. DIBAM, La Serena.

Boisset, G., Z. Seguel y O. Campana 1971. Las fechas radiocarbónicas y la ocupación temprana del litoral en las provincias de Concepción y Antofagasta en relación con las variaciones del nivel marino holocénicas. Resúmenes del VI Congreso Nacional de Arqueología Chilena. Universidad de Chile, Santiago.
Campbell, R. 2015. Nota historiográfica sobre las transcripciones del "Congreso Internacional de Arqueología de San Pedro de Atacama" y la creación de la Sociedad Chilena de Arqueología. Serie Monográfica de la Sociedad Chilena de Arqueología 5:1-25.

Ferrada, M. 1963. Revolución Arqueológica en San Pedro de Atacama. En Viaje 354:11-13.

Montané, J., P. Núñez, V. Zlatar, L. Núñez, B. Marinov, J. Salazar, N. Vergara y B. Bustos 1972. La arqueología en el norte de Chile: su estado y perspectiva de desarrollo en el tránsito hacia el socialismo. En Informe presentado en la Comisión de Ciencias Humanas del 1er Congreso de Científicos organizado por CONICYT, pp. 5-12. Santiago.

Núñez, L. 1966. Recientes fechados radiocarbónicos de la arqueología del norte de Chile. Boletín de la Universidad de Chile 64/65: 32-41.

Núñez, L. 1976. Registro regional de fechas radiocarbónicas del Norte de Chile. Estudios Atacameños 9:14-123.

Orellana, M. 1993. 30 años de docencia universitaria en la disciplina arqueológica. Boletín de la Sociedad Chilena de Arqueología 17:26-29.

Orellana, M. 1996. Historia de la Arqueología en Chile. Bravo y Allende Editores, Santiago.

Spahni, J. 1967. Recherches archaeologiques a l'embouchure du Rio Loa (Côte du Pacifique-Chili). Journal de la Société des Americanistes 56(1):181-239. 


\section{Notas}

1 Cabe revisar simplemente la lista de los Miembros Fundadores de la Sociedad Chilena de Arqueología (Boletín especial de 1995) o la de los participantes al Primer Congreso Nacional de Arqueología Chilena de San Pedro de Atacama para notar el dominio de género dentro de la academia arqueológica nacional de aquellos años (Campbell 2015; Ferrada 1963).
2 Otra cosa es que la mayoría lo olvide fácilmente, ya sea debido a la falta de lectura o porque el tiempo escasee para la reflexión.

3 Antes de ella solo investigadores extranjeros lo habrían realizado, como G. Mostny y J. Bird para Quiani (Mostny 1967), mientras que el resto se había dedicado al fechado de contextos fúnebres (Núñez 1966, 1976; Spahni 1967). 